\title{
No rastro do que transtorna o corpo e desregra o comer: os sentidos do descontrole de si e das "compulsões alimentares"*
}

Mônica de Oliveira Nunes ${ }^{1}$

Liliane de Jesus Bittencourt²

NUNES, M.O.; BITTENCOURT, L.J. Tracking what troubles the body and upsets eating: the meanings of loss of self-control and "eating compulsions". Interface - Comunic., Saude, Educ., v.17, n.44, p.145-57, jan./mar. 2013.

We proposed to examine the phenomenon of somatic identities, understood as new modes of perception and new socially established relationships with the body, and with food and eating, including abnormal ways of eating that do not necessarily constitute pathological conditions. We followed a phenomenological and interpretative theoretical perspective, making use of the corporeity concept that was developed by Thomas Csordas based on MerleauPonty's body perception concepts, and on the socially informed body originating in Bourdieu's habitus concept. We focused our analysis on the narratives of women who drew up their paths according to corporal turning points, thereby aiming to elucidate corporified sociocultural and affective dynamics, interpreted in relation to ethnic identity, social class and gender. We discuss the paroxysms of modern individualization, in which, through eating compulsions, the individual body takes upon itself the huge task of expressing, giving meaning to and reversing the group's ills.

Keywords: Corporeity. Somatic identities. Phenomenology. Racial relationships. Eating compulsion.
Propomos examinar o fenômeno das identidades somáticas, entendidas como novas formas de percepção e novas relações socialmente estabelecidas com o corpo, com o comer e a comida, incluindo modos alterados de alimentar-se que não se configuram necessariamente enquanto patologias. Utilizamos uma perspectiva teórica fenomenológica e interpretativa, valendo-nos do conceito de corporeidade, desenvolvido por Thomas Csordas, construído a partir dos conceitos de percepção corporal de Merleau-Ponty e do corpo socialmente informado, advindo do conceito de habitus de Bourdieu. Centramos a análise em narrativas de mulheres que elaboram suas trajetórias a partir de pontos de virada corporal, buscando elucidar dinâmicas socioculturais e afetivas corporeificadas, significadas a partir de pertencimentos étnicos, de classe social e gênero. Discutimos os paroxismos da individualização moderna, onde, por intermédio das compulsões alimentares, o corpo individual toma a si a enorme tarefa de expressar, significar e reverter os males do grupo.

Palavras-chave: Corporeidade. Identidades somáticas. Fenomenologia. Relações raciais. Compulsão alimentar.
"Elaborado com base em Nunes et al. (2006); pesquisa financiada pelo CNPq (Proc. 409718/ 2006-8, edital MCTCNPq/MS-SCTIE-DECIT n.26/2006) e aprovada pelo Comitê de Ética do Instituto de Saúde Coletiva.

1 Instituto de Saúde Coletiva, Universidade Federal da Bahia. Rua Basílio da Gama, s/nº, Campus Universitário do Canela. Salvador, BA, Brasil. 41.10-140. nunesm@ufba.br 2 Área de Saúde Coletiva, Curso de Nutrição, Universidade Federal do Recôncavo da Bahia. 


\section{Introdução}

Nas últimas duas décadas, encontra-se uma literatura grandemente interessada pelas novas modalidades de comportamento alimentar. Normalmente, ela tende a se focalizar em um recorte que aborda quadros patológicos mais graves, como os transtornos do comportamento alimentar - TCA, ou em aspectos mais genéricos que afetam grupos populacionais mais alargados, situados no que tem sido chamado de identidades somáticas (Ortega, 2003). Estas últimas implicam novas relações socialmente estabelecidas com o corpo, mas, também, com o comer e a comida, incluindo modos alterados de alimentar-se, que não se configuram necessariamente enquanto patologias propriamente ditas. O que propomos neste artigo é examinar esses últimos fenômenos, significados pelas pessoas como formas inadequadas de se relacionarem com o comer, em geral associadas a transformações corporais percebidas como indesejadas.

Nossa hipótese é de que essas expressões de um comer desequilibrado/desregrado e de um corpo transtornado podem ser formas privilegiadas de manifestar relações social e afetivamente conflitivas com o mundo e com o outro. Nesse sentido, essas manifestações se situam em um continuum com modos normais de reagir àquilo que produz mal-estar, mas, apesar disso, lançam pistas interessantes sobre fenômenos que produzem uma ruptura com formas habituais de agir e de configurar o corpo, e que, por isso, entram no rol dos quadros patológicos. Como exemplo dessa ruptura dentro de um continuum que incorpora comportamentos de controle consciente sobre o corpo pela via alimentar, Espeitx (2002) chama a atenção para o que cunha de restrição alimentar autoinduzida. Para a autora, esta denominação seria mais abrangente já que pressupõe explicações sociais distintas para um fenômeno presente em diversos momentos históricos, destacando, porém, a importância da pressão sociocultural como desencadeadora, que faz com que qualquer predisposição genética, biológica, ou psíquica, de nível individual para o mesmo se converta em "realidade". Essa pressão estaria fortemente associada, na atualidade, ao modelo estético da magreza, reinterpretado em termos de sucesso profissional, aceitação afetiva e sexual, valorização moral, entre outros.

A centralidade do corpo no mundo contemporâneo se reflete em uma literatura abundante que o toma como objeto e que o analisa nas suas transformações na experiência dos sujeitos modernos (Featherstone, 2010; Coelho, Severiano, 2007; Wainwright, Turner, 2003). Autores da tradição foucaultiana apresentam a relação estreita entre a ação do Estado sobre os corpos e a mediação da biomedicina (Kaufert, 2000). Essa relação se alarga pelo intermédio de uma biopolítica que controla as populações, especialmente pela regulação de fenômenos como o nascimento, o adoecimento e a morte (Fassin, 2000). Mais recentemente, autores, como Rabinow (1992), propõem que estamos em uma sociedade pós-disciplinar, onde grupos se organizam a partir de novas identidades e práticas, tendo interiorizado o controle, exercitando o que ele chama de uma biossocialidade. No bojo dessas mudanças, nascidas da interação entre recursos tecnológicos e midiáticos, com forte influência das biotecnologias, surgem as identidades somáticas. Estas viriam manifestar a externalização das subjetividades, a diluição da alma e da introspecção, e a proeminência do corpo como forma de manifestação de si, em uma fusão do self com o corpo (Ortega, 2003).

Ora, se essas abordagens iluminam o entendimento dos efeitos do biopoder acerca da normatização da vida e das representações e ações sobre o corpo no mundo contemporâneo, tais como a preocupação excessiva com a alimentação, elas tendem a se tornar muito generalizadoras, deixando de explorar os múltiplos significados que essas experiências corporais podem produzir em diferentes grupos e pessoas. Perguntamo-nos: em que medida esse idioma corporal forte, entre aqueles que o utilizam, não está servindo para comunicar aspectos diferentes da experiência singular e coletiva? Tomando a preocupação com o peso e com o alimentar-se, que particularidades interpretativas esses fenômenos podem nos indicar? Para explorarmos essas questões, de uma perspectiva fenomenológica, orientada pelo conceito de corporeidade presente no trabalho de Thomas Csordas (2008), lançaremos mão de narrativas produzidas por mulheres escolares jovens, situadas a partir de pertencimentos sociais e étnicos distintos, elucidando dinâmicas socioculturais e afetivas corporeificadas, decodificadas a partir da materialidade percebida do corpo e de mudanças da relação com o comer. 


\section{Perspectiva teórico-metodológica}

O presente artigo é elaborado a partir de dados produzidos no estudo "O padrão de beleza socialmente construído na gênese de transtornos do comportamento alimentar em mulheres negras de Salvador/Bahia", onde três jovens de escolas de Ensino Médio e nove jovens universitárias foram entrevistadas a partir de um roteiro que explorou as seguintes temáticas: mudanças corporais como marcos em uma história de vida; ideais e cuidados com o corpo; diferenças raciais e a valorização do corpo; situações de discriminação e rejeição, vivências corporais e a cidade de Salvador. O estudo foi aprovado pelo comitê de ética em pesquisa do Instituto de Saúde Coletiva da UFBA.

Para analisar as vivências corporais relatadas pelas jovens, o conceito de corporeidade (embodiment) proposto por Csordas (1993) será utilizado, tal como ele o constrói, a partir de seus dois analisadores fundamentais: os conceitos de percepção, na perspectiva de Merleau-Ponty, e de prática, na concepção de Bourdieu. Há, entre esses dois últimos autores, uma convergência na importância que ambos conferem à ruptura com uma perspectiva racionalista na compreensão do corpo, respectivamente desenvolvida a partir da noção de corpo próprio e do conceito de habitus. No entanto, enquanto o primeiro privilegiaria o aspecto pré-lógico e singular da experiência no mundo, o segundo destacaria a característica inconsciente da incorporação do social pelos indivíduos.

Para Merleau-Ponty (1994), a compreensão de corporeidade situa-se no colapso empreendido na dualidade objeto-sujeito. Em uma perspectiva gestáltica, o corpo é entendido por esse autor como um cenário (um fundo) em relação com o mundo, e a consciência é o corpo projetando a si próprio no mundo. Diferentemente de outros objetos, a percepção do corpo próprio é contínua, não estando ele diante de nós, mas ao nosso lado e, até certo ponto, confundido com o próprio ser. Essa mesma qualidade justifica o fato de que temos consciência do mundo através dele, sendo o corpo, para este autor, um "pivô do mundo" (Merleau-Ponty, 1994, p.122). A experiência do corpo no mundo se alicerça no fato de que ajo no mundo através do corpo, vivenciando tempo e espaço em uma perspectiva de não-exterioridade: "não estou no espaço e no tempo; eu sou no espaço e no tempo, meu corpo aplica-se e os abarca" (Merleau-Ponty, 1994, p.195).

Desse modo, a percepção seria um processo encarnado desde o seu começo, o que quer dizer que os objetos não preexistem à mesma, mas ganham existência a partir da intencionalidade que lhes é dirigida e da relação de materialidade que se estabelece entre corpo e objeto. Assim, a percepção é pré-objetiva, no sentido de que ela não começa nos objetos; no entanto, ela não é pré-cultural, sendo precocemente imersa em um mundo de valores e de símbolos. Ainda, as formas de percepção são transformadas histórica e culturalmente, juntamente com os modos de existência (Benjamin 1935 apud Valverde, 2003). O corpo é, desse modo, habitado pelas transformações dos modos de existência, das formas de sociabilidade, dos valores morais e econômicos, das dinâmicas relacionais, dos ethos culturais e das ecologias ambientais.

Se podemos tomar como exemplo, no polo situado no extremo do nosso tema de estudo, as percepções patológicas acerca do corpo, veremos que os aspectos do corpo, que são colocados em evidência nos TCA e na obesidade, em contextos culturais e históricos diferentes (Ferreira, Magalhães, 2005), não são os mesmos, ainda que o fenômeno (nesse caso, o comportamento alimentar) possa se apresentar de forma muito semelhante. Estudos mostram que a questão relacionada à fobia do peso, ou ao pavor da gordura, não está presente em todas as culturas como um sintoma relevante. Mesmo nos países ocidentais, especialmente nos Estados Unidos, faz-se a hipótese de que a centralidade desse aspecto na definição do padrão dos TCA surge no bojo da tensão entre mudanças culturais que apresentam o corpo magro como ideal de beleza e o aumento da prevalência de obesidade nesses países (Hsu, Lee, 1993). Ora, a percepção do corpo próprio é processada na interface dessa tensão que, incorporada, orienta a experiência de quem apresenta elementos de vulnerabilidade na sua história.

Em contextos culturais diferentes, outros desafios estão presentes nas significações encontradas, como, por exemplo, uma estratégia de retardar a maturação sexual observada entre mulheres japonesas e, assim, resistir a demandas sociais ligadas à vida adulta (Crisp, 1980). A tensão produzida, no Japão contemporâneo, entre o valor central atribuído ao casamento e à maternidade e as novas expectativas culturais que levam as mulheres a desejarem outros padrões de relação de casal, mais pautados na 
intimidade e na paixão amorosa, tem sido analisada como fundamental no aumento de casos de TCA nesse país (Pike, Borovoy, 2004). Por fim, para amenizar perspectivas alarmistas, Cáceres (2005), estudando 20 jovens catalães e referindo-se, não aos TCA propriamente ditos, mas a dietas alimentares, indica que essas preocupações entre os jovens podem conviver com preocupações com o prazer e com a saúde, e produzir, ao longo do tempo, hábitos alimentares perfeitamente saudáveis. Destaca, no entanto, a diferença de gênero, no que diz respeito à percepção da imagem corporal e aos recursos dietéticos mobilizados para modificá-la, estando os rapazes praticamente imunes a essas preocupações quando comparados às mulheres.

A partir dessas diferenças, pode-se pensar que a corporeidade é expressa por "figurações [que] estruturam o imaginário do corpo tanto quanto elas modulam a substância e a espessura de uma interioridade que são a base da constituição de si da identidade" (Durif-Bruckert, 2003, p.73), mas essas articulações entre dados fisiológicos e vividos somatopsíquicos se revelam em um contexto específico de modelos e de linguagens sociais. Em cada contexto social, o corpo é colocado em cena, inscrito em codificações sociais sobre ideais de beleza e sobre imaginários corporais, para enunciar dinâmicas que colocam em jogo relações afetivas, relações de gênero, relações raciais e relações de poder.

No entanto, para avançar na compreensão do modo pelo qual os agentes (sujeitos) incorporam o mundo social, a escolha de Bourdieu (2007), na construção do conceito de corporeidade, é decisiva. Nessa perspectiva, o corpo, informado socialmente, é o "princípio gerador e estruturador das práticas e das representações" (Ortiz, 1983, p.61), sendo a consciência a forma do cálculo estratégico articulado a um sistema de potencialidades objetivas, que constitui o habitus. Pelo habitus, se procederia à incorporação de estruturas sociais sob a forma de estruturas de disposições. O eu, que compreende de forma prática o espaço, seria um sistema de disposições que ocupa uma posição e toma posição. Freitas, Minayo e Fontes (2011) se utilizam, inclusive, desse conceito para a proposta de uma abordagem compreensiva no campo mais vasto da antropologia da alimentação, salientando que "os habitus [alimentares] são textualizáveis como inscrições significativas da cultura e podem ser interpretados" (Bourdieu, 2007, p.34).

O conceito de corporeidade, assim constituído, permite uma análise das narrativas sobre o corpo em uma perspectiva experiencial que, ao mesmo tempo, desvela os aspectos sociais encarnados nas transformações corporais percebidas e significadas pelas mulheres estudadas. Para produzir as narrativas que estudamos, concebemos uma técnica que julgamos sensível para esse tipo de estudo, estimulando as mulheres a falarem das percepções do corpo a partir do que chamamos de pontos de virada corporais. Esse conceito nasce inspirado pelo texto de Mishler (2002), onde o autor indica que as narrativas não são construções lineares, sendo tecidas a partir de um jogo temporal caracterizado por frequentes flashbacks, sobre os quais os pontos de virada (PV) no curso de uma biografia incidem como elementos decisivos, conduzindo a ressignificações de uma história pessoal. No caso do nosso interesse, sugerimos que a atenção voltada para o corpo é exacerbada em momentos onde há mudanças mais evidentes do mesmo, interferindo na apreensão do ser no mundo. Essas mudanças podem ocorrer em função do ciclo de vida (puberdade, menopausa, velhice, entre outros), alterações fisiopatológicas (disfunções hormonais), ou padrão alimentar (excesso ou redução na ingesta, ritmo modificado do comer, ou pela natureza e qualidade dos alimentos escolhidos).

No entanto, percepções corporais também são produzidas a partir de: transformações normativas, mudança de valores, cursos de histórias de vida, alterações sensoriais, ou cultivo de novas sensibilidades. Com isso, afirmamos que percepções de mudanças corporais e de rotinas alimentares são biopsicossocioculturalmente situadas, uma vez que são geradas a partir: da confluência de biologias locais (Lock, 1993), de atribuições de valores a estéticas corporais (ideais de beleza), de formas de relações sociais, afetivas e políticas, de modos de educação da sensibilidade, de experiências do sensível advindas dos usos do corpo, de significados simbólicos e de manuseios econômicos do corpo.

Estudar as percepções corporais a partir dos seus PV é situar as narrativas em uma trajetória biográfica onde os modos somáticos de atenção (Csordas, 1993) e suas transformações são privilegiados. O objetivo de aguçar as sensibilidades para identificar momentos de mudanças corporais julgadas significativas se completa com a busca das cadeias de interpretações atribuídas a essas mudanças. Em seguida, realizamos uma análise de narrativas atenta para as expressões acerca do corpo 
(o corpo falado) nas suas metamorfoses (pontos de virada), destacando figuras de linguagem que condensam significados simbólicos atribuídos à corporeidade. Neste artigo, restringimos essa análise a histórias contadas por duas das jovens entrevistadas, com nomes fictícios.

\section{O descontrole da boca (e de si) como regulador/revelador do que excede nas relações sociais}

Sereia tem 27 anos e se autodefine como negra. Nascida em um bairro popular de Salvador, começou a trabalhar como babá aos 13 anos e, atualmente, é doméstica, cursa o $3^{\circ}$ ano do $2^{\circ}$ grau e é católica. Foi criada com a mãe, quatro irmãs e um irmão, depois que seus pais se separaram.

A sua narrativa constrói um enredo provocado por uma questão que lhe propomos inicialmente: "Se a gente pedisse a você para contar sua história a partir de mudanças que aconteceram no seu corpo, como você contaria?" Sereia enfatiza dois momentos principais da sua história corporal: o primeiro circunscreve uma fase onde era "magrinha, bonitinha", que ela situa nos seus 15 anos, e do qual fala muito pouco; e um segundo, constituído a partir de um ponto de virada, aos 22 anos, onde ela começou a aumentar exageradamente de peso, sobre o qual ela centra a entrevista. A tessitura das causas ligadas ao aumento de peso toma forma de caleidoscópio etiológico de fatores biológicos, psicológicos e sociais, articulando as causas umas às outras em composições não excludentes. Não se observa linearidade nessa composição, o tempo narrativo sendo desenhado de modo a que frequentes flashbacks ressignifiquem e re-hierarquizem fatores interpretativos, dando densidade à história.

$\mathrm{Na}$ relação com o seu aumento de peso, a mudança de rotina alimentar é o elemento que primeiro aparece. Sereia indica pistas sobre o seu padrão alimentar, inicialmente imposto por um ritmo de trabalho como empregada doméstica, associado à sua vida escolar: come pela manhã, não almoça e come um acarajé à noite, antes da escola. Em seguida, há um período de maior regularidade alimentar, quando o namorado se dispõe a levar o seu almoço no trabalho. Por fim, o padrão relacionado mais exclusivamente ao trabalho de empregada doméstica: a necessidade de sair cedo de casa, comendo quase nada, a merenda calórica no meio da manhã (chocolate ou suco e dois pães), o almoço tardio (às $15 \mathrm{~h}$, um prato cheio de farinha) e, à noite, não come nada. O que, para Sereia, compõe um padrão alimentar "normal" comporta sempre saltar algum horário de alimentação, com duas alimentações principais do dia. O que ela interpreta como sendo "compulsão alimentar" (ela usa essa expressão) é o fato de acrescentar dois horários de alimentação aos anteriores, no caso, ao acordar e à noite.

Para lidar com esse comer exagerado (sentir-se "aliviada de desgaste de barriga cheia demais"), ela passa a colocar o dedo na garganta para vomitar, tendo aprendido a fazer isso com uma telenovela que apresentava uma personagem com quadro de bulimia, como forma de discutir o tema na sociedade. Paradoxalmente, no seu caso, isso serviu como modelo de conduta. Foi assistindo outro programa, o Fantástico, que descobriu que esse era um comportamento "patológico", com risco de morte, razão pela qual decidiu pará-lo: "Então eu preferi parar e ficar do jeito que eu tava, mais saudável do que ficar continuando e pegar uma doença braba".

Como segundo fator causal, relaciona a perda de um bebê desejado, aos 22 anos, fruto do aprofundamento da sua relação amorosa, seguida de novas tentativas, sem sucesso, de engravidar, e da separação do namorado. Esse momento de grande sofrimento produz efeitos na sua vida, fazendo surgir comportamentos inabituais interpretados como inadequados e nocivos. O padrão alimentar é interpretado como desregrado e aparece como sintoma. A "liberação" do comer reflete-se no corpo que excede o peso, que se revela ao olhar alheio, que reduz a autoestima e que provoca outras doenças. Na busca de entendimento dessas mudanças, uma forma mais holística e complexa de se (nos) interrogar se põe em marcha:

“Porque assim, eu também já percebi em mim que assim, eu, hoje em dia, já tô tendo atitudes que eu nunca tive antes. [...] Mas assim, às vezes eu como escondido e não tenho necessidade disso [...]. Deixe eu ver, às vezes eu faço coisas que, assim, atitudes minhas também de até responder às pessoas, eu era bem tímida, bem tímida mesmo, que, pra fazer as coisas, vixe Maria, eu pensava dez vezes! Hoje em dia, vou dizendo tudo na lata, se for de falar, eu tô 
falando, se for de responder, eu estou respondendo. Então, assim, eu não sei se ainda tô tendo algum transtorno, por eu tá engordando e tá mexendo com o meu psicológico, ou se é um amadurecimento meu que está fazendo que eu fique assim, mas eu, pelo que eu me lembro bem, eu comecei a ter essa atitude depois que eu perdi esse filho, como eu falei [...]".

Paradoxalmente, esses comportamentos se associam à liberação da palavra e à mudança da sua forma de ser. A perda do filho parece liberá-la de um modo comedido de ser, perdendo, assim, uma Sereia, tímida e contida, e ganhando uma outra, mais descontrolada, desbocada (no comer e no falar) e corpulenta. Durif-Bruckert (2004), falando do sistema digestivo, afirma que a experiência da corporeidade está ligada à imprevisibilidade do movimento, uma vez que a flexibilidade das suas bordas, daquilo que, no organismo, permite reter ou escorrer, resistir ou escapar, é o que produz a incerteza da sua solidez, ameaçando transbordar o próprio corpo. Podemos pensar que, no caso do sistema reprodutivo, essa imprevisibilidade se transforma em certeza quando um aborto espontâneo advém, o objeto da perda vindo colocar em questão a capacidade do corpo "em prender e em guardar alguma coisa". Isto aponta para a questão da desmesura, do descontrole e da desordem, esferas de sentido às quais um novo corpo e sua vivência podem abrir o acesso.

Para complexificar essas esferas, um terceiro bloco de significados causais surge ligado à relação estabelecida com a sua patroa. O desenvolvimento das temáticas sobre relações inter-raciais e percepção de racismo aprofundou-se quando exposta a relação com a senhora idosa da qual Sereia se ocupa há alguns anos, estando fortemente ligadas a relações de classe que se estabelecem no espaço do trabalho doméstico. Aqui o paradoxo das ambivalências nas relações raciais brasileiras, que envolvem o mito da cordialidade e da tolerância racial (Guimarães, 2005), se reflete na história de Sereia. Atentar para as contradições no discurso da sua patroa, no que tange ao preconceito racial, sensibiliza Sereia para as ambivalências presentes na relação desenvolvida entre elas em uma perspectiva de relação de classe. Esses aspectos relacionais lançam uma pista do que poderia significar o comer no emprego e a razão de esse ser um fator de desregramento do padrão alimentar.

\footnotetext{
"Por exemplo, essa coisa mesmo de até comer escondido, eu acho isso, não tem necessidade de eu comer escondida. Aí às vezes, eu, às vezes, eu tô comendo assim, aí continuo com a... [rindo] como como o quê. Eu também não sei se é porque eu estou escondendo dela, porque ela diz: 'pode comer o quanto você quiser'. [...] Fora o trabalho, mas em casa eu fico à vontade. Ainda tem isso também, comer de barriga cheia, às vezes eu tô sem um pingo de fome, mas eu chego em casa, acho uma coisa gostosa que tá ali, ali eu boto pra dentro, tenho que comer".
}

Esse padrão alimentar repete o que se encontra na literatura acerca de comportamentos compulsivos ("comer mesmo sem vontade") e as estratégias desenvolvidas para escondê-los das outras pessoas. Contextualizando-o, percebe-se que o comportamento de Sereia associa-se a uma relação de desconfiança em relação à palavra da patroa. Essa desconfiança é fruto do que é descrito mais tarde na entrevista e que deixa entrever que a patroa frequentemente diz uma coisa na sua presença, mas pensa, ou faz outra, na sua ausência. A literatura que analisa o trabalho doméstico está cheia de exemplos sobre os aspectos ambivalentes da relação que envolve patroa e trabalhadora de serviços domésticos, informando sobre seus efeitos psicologicamente negativos (Xavier, 2005). Nesse caso, o comer escondido, uma relação perturbada com o comer, pode indicar uma relação conflituosa e um desejo de vingar-se da patroa. O comer à vontade, por sua vez, que faz em sua própria casa, pode indicar a possibilidade de comer em um espaço de maior liberdade e intimidade, ou de liberar-se da opressão (e, portanto, comer mesmo quando não está com vontade).

Sereia relata situações cruciais onde flagrou a patroa difamando a sua imagem e a da sua família em telefonemas para próximos, ou soube de a mesma ter falado mal do seu trabalho na casa de uma amiga. A equação lógica, que ela formula a partir da sua relação com a patroa - "eu me comportava bem e, ainda assim, ela falava mal de mim pelas costas" - nos convida a entender que não vale a pena ser assim tão correta com quem não merece, de que é melhor não esconder o sentimento que o outro 
provoca em si, e de que é preciso ter coragem de tomar uma decisão no sentido de romper com esse estado de sofrimento:

“[...] mas eu já tô vendo já, que acho, desse ano, eu sempre tenho estado, daqui eu não passo, eu já tô vendo na minha cabeça mesmo de sair, porque aqui tá virando muito a minha cabeça, me deixando muito mesmo, atordoada mesmo, porque também tem emprego, tem trabalho que a gente pega que deixa a gente de um jeito que a gente ou pira de vez, e, pra não pirar, tem que sair. Aí, no meu caso, é o que tá pra acontecer".

Longe de interpretações categóricas para o vivido, na narrativa de Sereia, as metamorfoses do corpo oscilam dentro de referentes culturais disponíveis, dentre os quais o sobrepeso como patologia. $O$ aumento de peso entra no caleidoscópio etiológico que ela compõe como aquilo que pode ser a fonte de perturbação psicológica na origem desse destempero. Em uma linha psicossocial de raciocínio, o comer compulsivo aparece como a liberação de afetos em maturação, condutores de eventos produzidos no interior de relações de poder e de opressão, mas, também, de situações de grande aflição. A "confusão da mente" à qual Sereia recorre como forma de expressão do conflito relacional de classes, frequentemente encoberto pela intimidade e pessoalidade que envolve a relação domésticapatroa (incluindo conflitos raciais e uma diferença geracional), traduz também o transtorno corporal, alimentar e comportamental. As certezas, que pareciam organizar a sua vida, se dissipam e são colocadas entre parênteses em um emaranhado de possibilidades de novas conexões de sentidos. A essa sensação de caos se superpõem sentimentos negativos, mas também positivos, que a orientam na direção de algumas intuições encarnadas (ao modo de Riobaldo: "eu quase que nada não sei, mas desconfio de muita coisa", em Rosa, 1956, p.16) que podem gerar novas consciências do estar no mundo e novas intencionalidades.

\section{O corpo como restaurador do que está fora de ordem}

Falamos do desregramento do corpo como marcador do que está fora de ordem no mundo psicossocial. A ideia se situa na experiência da transformação do corpo como termômetro de relações sociais disruptivas e como indicadora de encarnação de sofrimento. Nesse sentido, os sinais do corpo, muitas vezes, se inscrevem em percepções sensitivas e pré-lógicas, difíceis de racionalização na imediatez da experiência, na perspectiva proposta por Merleau-Ponty onde a consciência é a projeção do corpo no mundo. O significado muitas vezes advém das transformações corporais sentidas e situadas em contextos de vida. Essas transformações sentidas, por sua vez, tendem a evidenciar mudanças ou ressignificações do meio social vivido, ou das relações sociais.

Como diz Valverde (2003), a partir da leitura de Benjamin, podemos perceber o mundo (e o corpo consequentemente) no sentido cinestésico, associado ao movimento, à mudança de tônus, de posição, ou de angulação, e, segundo o autor, essa percepção normalmente se faz menos pela atenção do que pelo hábito, uma condição ativa e coletiva que se configura em uma pragmática. Ora, podemos pensar que o que acontece nos chamados pontos de virada corporais é que colocamos em suspensão esse sentido habitual e prestamos atenção ao corpo, às suas mudanças, e, como consequência, nos interrogamos sobre as condições geradoras das mesmas.

Isso é corroborado na perspectiva de Benjamin, onde as diferentes formas de sensibilidade são diferentes padrões de recepção adquiridos pelos hábitos introduzidos por diversos meios e sustentados em diferentes tecnologias. A recepção "é sustentada pela percepção sensorial, mas não se reduz a ela, uma vez que opera num ambiente discursivo e segundo uma disposição (um pathos), que se traduz em determinados usos e costumes" (Valverde, 2003, p.21). Nessa perspectiva, pensar corporeidade é situar-se no domínio de uma práxis - práticas corporais informadas por discursos sociais. Essa compreensão nos impulsiona a analisar as mudanças corporais descritas por nossas entrevistadas, incluindo aí os seus transtornos, a partir de uma matriz cultural que lhes fornece idiomas corporais compartilhados socialmente, ao mesmo tempo em que lhes permitem significá-los em um contexto singular. Mais um exemplo permite elucidar essa proposta. 


\section{A menina de ouro - o jogo de corpo e a virada do jogo}

Céu tem 24 anos, nascida em Salvador, se autodefine como branca, pertence à classe média baixa e é estudante de psicologia em uma faculdade privada. Relata que, depois dos nove anos de idade, sempre foi gordinha, embora sempre tenha vivido o "efeito sanfona" (engorda-emagrece). Faz uma retrospectiva das idades e do seu estado corporal. Quando criança era magra, aos nove ficou gordinha, aos treze era esbelta, "bonitona", entre os 17 e os 18 anos, foi o período crítico em que foi morar em Brasília, com a tia, tendo sofrido pelo fato de não ter amigos, não ter namorado, não estar na sua casa, sentir-se isolada e preterida. Isso gerou muita ansiedade, expressa no desejo compulsivo de comer, que ela define assim:

"É, se eu ficar parada, o dia todo na televisão, dá vontade de comer. Se tiver desocupada a mente, aí dá vontade de comer. [...] É... Aí vou fazer brigadeiro. E tudo é motivo pra mim comer... se eu tiver estressada, aí eu como. É como se acalmasse alguma coisa, me deixasse tranquila, principalmente, mais nesses dias, ou quando passo alguma raiva".

Aumentou dez quilos e isso só se regularizou quando voltou para Salvador, onde frequentou academia de ginástica e voltou a ter amigos. No entanto, ainda viveu momentos de sofrimento com o peso, especialmente expresso na dificuldade em arranjar namorado. Esse fator reaparece frequentemente, evocando relações de gênero vividas como difíceis, o que, na sua história, parece ocupar um lugar crucial na definição das suas experiências corporais:

"Quando eu saía com minhas amigas, que eram mais magras, o pessoal só olhava pra elas e pra mim não. Eu não tinha nem vontade de ir pra praia, porque eu me sentia apagada. Me chamavam e eu não ia, porque eu sentia que era diferente. Até pra conversar, era como se eu fosse a última opção. [...]".

Essas cenas a fazem se sentir discriminada, produzindo-lhe um sentimento de invisibilidade que, em revanche, provoca-Ihe um comportamento de retraimento, refletido na busca de escolher roupas que disfarçassem o peso, reforçando essa invisibilidade. Efeitos paradoxais se produziam ao comer mais quanto mais era rejeitada ("Ah! Já tô gorda mesmo, vou comer..."). Por outro lado, Céu compreende que o olhar masculino fixado no corpo feminino era exatamente aquilo que, ao objetificar a mulher, rejeitava-a. Essa compreensão parece liberá-la da objetificação do próprio corpo, percebendo-se na totalidade corpo-eu (ou corpo-sujeito):

"É que a gente tá bem, mas, quando a gente ouve alguém falar [criticamente], que se olha no espelho, já se vê diferente, mas eu procurei não falar e trabalhar a minha cabeça. Já fui respondendo que quem tem que gostar de mim tem que gostar do que eu sou, não do meu corpo não [...]".

O grande ponto de virada é atribuído por Céu ao fato de ter entrado para a academia de boxe, mais ou menos aos 22 anos. Nesse período passou a ser valorizada pela sua capacidade de lutar, e não pelo corpo que tinha, passou a ser estimada pelo professor e colegas, era uma das únicas mulheres do grupo, mas, sobretudo, a que lutava melhor, sendo considerada "a menina de ouro". Tudo isso teve um importante efeito sobre a sua autoestima, afirmando, com ar de surpresa, que até passou a ser considerada bonita. A partir daí, desenvolve a ideia de que é preciso que você esteja bem consigo para atrair as pessoas, embora o oposto pareça ter acontecido primeiro: pessoas em torno passaram a valorizá-la por sua habilidade em lutar e isso parece ter reencantado seu corpo feminino. Seu discurso indica também a importância da socialização entre homens de outra classe social, com outro modelo de beleza física, além de dois efeitos paradoxais produzidos: 1) pela "distinção social" de que era portadora: a "patricinha" que se integrou ao grupo pelo intermédio do valor da luta; 2) pela desfocalização do corpo-objeto feminino, onde o corpo-sujeito assume a liderança, através de uma luta 
masculina. Não se pode desconsiderar que o filme "Menina de Ouro" tenha aportado capital simbólico e favorecido a sua inclusão e valorização.

O trabalho de Loïc Wacquant (2002) sobre lutadores de boxe oferece o conceito, advindo da teoria de Bourdieu (2008), de capital físico, indicando-o a partir da forma e do estilo do corpo, o estilo do boxeador. Nesse caso, o habitus individual seria modulado pelo habitus institucional. Observadas as ressalvas por não se terem elementos suficientes para falar da transformação do corpo de Céu em um corpo boxeador, sugerimos, no entanto, que ela incorpora a luta como etos, uma luta que implica o sentido profundo de identidade: o amor-próprio, que ela traduz como autoestima. Esta é descrita a partir de mudanças em dimensões distintas da vida: o olhar sobre si mesma, a maior harmonia com o corpo e, consequentemente, as escolhas de roupas que não o desvalorizem, a afirmação de si na definição de qual relacionamento esperava para si (relação de gênero), o olhar sobre o mundo das pessoas de classe popular, que passam a ser seus amigos, e a aquisição de um novo lugar social, permitido pelo boxe, onde é convidada a ser "modelo para os outros". O estar bem no próprio corpo dialoga com o que é concebido como a exteriorização do feio:

\footnotetext{
"O vestir também passa isso e era como eu gostava de me vestir, assim. Mas acho que antes eu me escondia e, pra não ser notada, eu acho que eu ficava logo folgada, mas agora não. [...] Eu não quero nada que eu veja que vai me botar mais pra baixo. A pessoa me vê mais gorda e eu falo: essa não é a roupa que eu tenho que usar não... aí eu vou mudando. Aí eu tô me sentindo bem com as roupas que eu tô vestindo, tô me sentindo bem e é isso".
}

A corporeidade se estende para além do corpo físico, envolvendo roupas, tatuagens, movimento, pinturas, enfim, tudo aquilo que constitua uma identidade, que, por sua vez, é mutante e relacional. Assim, Céu fala sobre Salvador, uma cidade onde as pessoas parecem bem entrosadas e à vontade com o corpo. No entanto, faz a ressalva de que, na praia, as mais magrinhas não tiram o short, as mais gordinhas não tiram a blusa. Remete isso a questões psicológicas, de autoestima, e afirma que as pessoas jogam com a aparência, tentando disfarçar o que se passa dentro de si, "porque, querendo ou não, é a aparência que conta". Por outro lado, a dissonância entre expressão individual e imposição social, sentida sob a forma de um sofrimento pela inadequação com um "padrão ideal de beleza", e as consequências desse sofrimento só podem existir porque o processo de incorporação desse ideal preexiste. Ou seja, o corpo que se projeta no mundo já é um corpo, como diz Bourdieu (2007), socialmente informado. Mais interessante, entretanto, é que, nessa dicotomia interioridade/ exterioridade, percebe-se um jogo, cuja dinâmica tensiona e colapsa a própria dicotomia, uma vez que, na perspectiva da corporeidade, não podemos distinguir exatamente um dentro e um fora, a não ser como recurso retórico ou como experiência vivida dentro do próprio jogo.

As estratégias de jogar com o corpo nos convidam, por sua vez, a decifrar "o que está em jogo" nessas situações. É essa explicitação que permite, inclusive, predizer o grau de sucesso ou fracasso no mesmo, pensados aqui em termos de felicidade ou infelicidade no jogo. Aqui pode-se sugerir que aquilo que algumas jovens descrevem como o "transtorno do corpo" ou o "desregramento alimentar", expressos sob o termo de "compulsão alimentar", serve para aclarar, por exemplo, formas de transgressão contra estéticas tiranizadoras, corpos objetificados, relações opressivas. Em outros momentos, esses fenômenos podem indicar a expressão hiperbólica da sociedade de excessos - excesso de consumo, para os sociólogos (Bauman, 1998), ou excesso de gozo, para os psicanalistas (Chemama, 2009). Pode-se antever ainda a tentativa de, metaforicamente, encarnar o caos, ou a desordem na qual estão mergulhadas as relações humanas. Em qualquer dessas expressões, tomadas isoladamente, ou agregadas, não apenas a vivência do transtorno, mas, também, a saída da situação de sofrimento podem ser vislumbradas a partir de táticas corporais, como mostramos no caso de Céu.

Ou, então, podemos pensar, como Estrela, uma outra entrevistada, que "brincar com o corpo" quer dizer experimentá-lo nas suas variações possíveis a partir da inclusão de artifícios: as lentes de contato, ou as tranças no cabelo. São coisas que se coloca e se tira, maleáveis. Existem também aquelas coisas mais permanentes, mais valorosas para a pessoa, e que têm uma relação identitária mais profunda, tal como a tatuagem. Não apenas com os signos maleáveis, mas, também, com modificações impressas ao 
corpo, é possível negociar mensagens, inclusive outras que não aquelas preestabelecidas nos clichês, como, por exemplo, quem usa tatuagem é vagabundo. Para Estrela, essas "brincadeiras com o corpo" falam menos de uma não-aceitação de si, configurando, sobretudo, formas de driblar certas faltas, lidar com jogos identitários com a alteridade, como ela diz: "Brincar de ser diferente um pouquinho, porque todo dia você se olhando do mesmo jeito, enjoa. [...] Tudo está aí pra gente usar, pra brincar, né? Se não fosse, não era nem pra existir. O que não é pra ser, não existe". Poderíamos pensar que o mal-estar ou o transtorno do corpo se instalaria, sobretudo, a partir da incapacidade de realizar essa brincadeira. Mas poderíamos também sugerir que significar o transtorno pode ser um modo de revelar, ou de reabrilo para o seu jogo, ou, quem sabe, para a brincadeira.

\section{A compulsão expressiva dos corpos}

Diversos autores falam da escalada do processo de individualização do mundo contemporâneo e a sua repercussão no cuidado de si (Foucault, 1984), um cuidado excessivamente centrado na atenção voltada para o corpo (Lipovetsky, 1993). O eu hedonista e autocentrado e o corpo perfeito aparecem como patognomônicos desse modelo. Por sua vez, esse modelo, não sendo do alcance de todos, é, entretanto, vendido como prêt-à-porter em emissões televisivas e em publicidades midiáticas. No outro lado da medalha, as patologias do corpo também são massivamente disponibilizadas para consumo, dentre as quais obesidades, compulsões alimentares e TCAs, tornando-se idiomas culturais de aflição, à mão para serem utilizados. No paroxismo dessa individualização, onde os limites do corpo seriam a expressão material, o que se observa, contudo, é, como diz Ehrenberg (1995, p.19), menos uma exibição narcísica da vida privada e mais a expressão de um "indivíduo incerto", excessivamente exigido do ponto de vista de uma performance de si. Para esse autor, "nós entramos em uma sociedade da responsabilidade de si: cada um deve imperativamente se achar um projeto e agir por si mesmo para não ser excluído do laço, qualquer que seja a fraqueza de recursos culturais, econômicos e sociais dos quais ele dispõe" (Ehrenberg, 1995, p.14-5, minha tradução).

Nesse sentido, quando o peso da construção do mundo é individualizado, onde cada pessoa é responsável pelo seu próprio sucesso e sobrevivência, cada um é deixado a si mesmo, os corpos passam a expressar-se compulsivamente desse lugar atomizado: seja ganhando espaço, tornando-se invasivo, obeso, seja na redução do corpo anoréxico, que reaparece no incômodo causado, seja pelo descontrole de si, revelado por um comer desregrado. Os sentidos relacionais do peso e do comportamento alimentar conduzem a uma tentativa de conter, pelo corpo, um mundo de excessos, a limitar relações opressivas pelo descontrole da boca, a compensar uma escassez relacional pelo excesso alimentar.

No entanto, tal como propusemos nesse texto, as identidades somáticas, inegavelmente um processo do mundo moderno, não ganham pleno sentido a não ser através de exames mais detalhados do modo como incidem e dos seus mecanismos de refração nos diversos grupos sociais e em histórias particulares. É desse lugar social, histórica e afetivamente situado, que se constituem as percepções do corpo, as suas experiências e as suas expressões. Menos afeito a rituais onde o corpo coletivo toma a proeminência, o corpo individualizado moderno, idealmente referido a uma tradução do si mesmo, encarna e é encarnado por relações sociais de classe, de raça, de gênero ou afetivas. Menos provido de espaços de experiência e de inversão simbólica, o corpo individual toma a si essa enorme tarefa de expressar, de significar e de reverter os males do grupo. 


\section{Colaboradores}

Mônica de Oliveira Nunes participou de todas as etapas da pesquisa e da redação de parte substancial do atual manuscrito. Liliane de Jesus Bittencourt também participou de todas as etapas da pesquisa e contribuiu com acréscimos relevantes ao conteúdo do texto, sobretudo aqueles que se referem às questões de corpo e etnicidade.

\section{Referências}

BAUMAN, Z. O sonho da pureza. In: O mal-estar da pós-modernidade. Rio de Janeiro: Jorge Zahar, 1998. p.13-26.

BOURDIEU, P. Razões práticas: sobre a teoria da ação. Campinas: Papirus, 2008. O conhecimento pelo corpo. In: Meditações pascalianas. Rio de Janeiro: Bertrand Brasil, 2007. p.157-98.

CÁCERES, J. La incidencia de la preocupación por la imagen corporal en las elecciones alimentarias de los jóvenes. Zainak, n.27, p.167-77, 2005. Disponível em: <http:// hedatuz.euskomedia.org/3811/1/27165177.pdf>. Acesso em: 28 fev. 2012.

CHEMAMA, R. Quelques remarques à propos de la bulimie ordinaire. J. Français Psychiatr., n.32, p.44-7, 2009.

COELHO, R.F.J.; SEVERIANO, M.F.V. História dos usos e desusos e usura dos corpos no capitalismo. Rev. Depart. Psicol. UFF, v.19, n.1, p.83-100, 2007.

CRISP, A. Anorexia nervosa: let me be. London: Plenum Press, 1980.

CSORDAS, T. Somatic modes of attention. Cult. Anthropol., v.8, n.2, p.135-56, 1993.

A corporeidade como um paradigma para a antropologia. In: Corpo/ significado/cura. Porto Alegre: Editora da UFRGS, 2008. p.101-46.

DURIF-BRUCKERT, C. Corps, corporéité et rapport à I'aliment dans les troubles du comportement alimentaire. Champ Psychosom., v.29, n.1, p.71-95, 2003.

EHRENBERG, A. L'individu incertain. Paris: Calmann-Lévy, 1995.

ESPEITX, E. El hambre autoinducido: lugar de encuentro entre lo biológico, lo psicológico, lo social y lo cultural. In: CONGRÉS DE ANTROPOLOGÍA "CULTURA \& POLÍTICA" DE LA FEDERACIÓN DE ASOCIACIONES DE ANTROPOLOGÍA DEL ESTADO ESPAÑOL - FAAEE, 9., 2002, Barcelona. Actas... Barcelona, 2002. Disponível em: <http://www.seiahs.org/article.php?id_article=4>. Acesso em: 7 nov. 2012.

FASSIN, D. Entre politiques du vivant et politiques de la vie: pour une anthropologie de la santé. Anthropol. Soc., v.24, n.1, p. 5-116, 2000.

FEATHERSTONE, M. Body, image and affect in consumer culture. Body Soc., v.16, n.1, p.193-221, 2010.

FERREIRA, V.A.; MAGALHÃES, R. Obesidade e pobreza: o aparente paradoxo: um estudo com mulheres da Favela da Rocinha, Rio de Janeiro, Brasil. Cad. Saude Publica, v.21, n.6, p.1792-800, 2005.

FOUCAULT, M. Histoire de la sexualité: le souci de soi. Paris: Gallimard, 1984. v.3.

FREITAS, M.C.S.; MINAYO, M.C.S; FONTES, G.A.V. Sobre o campo da alimentação e nutrição na perspectiva das teorias compreensivas. Cienc. Saude Colet., v.16, n.1, p.31-8, 2011. 
GUIMARÃES, A.S.A. Racismo e anti-racismo no Brasil. São Paulo: Editora 34, 2005.

HSU, L.K.G.; LEE, S. Is weight phobia always necessary for a diagnosis of anorexia nervosa? Am. J. Psychiatr., v.150, n.10, p.1466-71, 1993.

KAUFERT, P. Screening the body: the pap smear and the mammogram. In: LOCK M.; YOUNG, A.; CAMBROSIO A. (Eds.). Living and working with the new medical technologies: intersections of inquiry. Cambridge: Cambridge University Press, 2000. p.165-83.

LIPOVETSKY, G. L'ère du vide: essais sur l'individualisme contemporain. Paris: Gallimard, 1993.

LOCK, M. Encounters with aging: mythologies of menopause in Japan and North America. Berkeley: University of California Press, 1993.

MERLEAU-PONTY, M. Fenomenologia da percepção. Trad. Carlos Alberto Ribeiro de Moura. São Paulo: Martins Fontes, 1994.

MISHLER, E.G. Narrativa e identidade: a mão dupla do tempo. In: LOPES, L.P.M.; BASTOS, L.C. (Orgs.). Identidades: recortes multi e interdisciplinares. Campinas: Mercado de Letras (CNPq), 2002. p.97-119.

NUNES,M. et al. O padrão de beleza estabelecido socialmente na gênese de transtornos do comportamento alimentar em mulheres negras de Salvador/Bahia. Projeto de pesquisa aprovado pelo CNPq. Salvador, 2006.

ORTEGA, F. Práticas de ascese corporal e constituição de bioidentidades. Cad. Saude Colet., v.11, n.1, p.59-77, 2003.

ORTIZ, R. (Org.). A sociologia de Pierre Bourdieu. São Paulo: Ática, 1983.

PIKE, K.M.; BOROVOY, A. The rise of eating disorders in Japan: issues of culture and limitations of the model of "Westernization". Cult. Med. Psychiatr., v.28, p.493-531, 2004.

RABINOW, P. Artificiality and enlightment: from Sociobiology to Biosociality. In: CRARY, J.; KWINTER, S. (Eds.). Incorporations. New York: Zone, 1992. p.234-52.

ROSA, J.G. Grande sertão: veredas. Rio de Janeiro: J. Olympio, 1958.

VALVERDE, M. Recepção e sensibilidade. In: (Org.). As formas do sentido. Rio de Janeiro: DP\&A, 2003. p.13-68.

WACQUANT, L. Corpo e alma: notas etnográficas de um aprendiz de boxe. Rio de Janeiro: Relume Dumará, 2002.

WAINWRIGHT, S.P.; TURNER, B.S. Reflections on embodiment and vulnerability. Med. Humanit., v.29, n.1, p.4-7, 2003.

XAVIER, S.S. É como se a gente estivesse em casa: representações e práticas acerca do trabalho e do risco à saúde no serviço doméstico remunerado. 2005. Dissertação (Mestrado) - Instituto de Saúde Coletiva, Universidade Federal da Bahia, Salvador. 2005. 
NUNES, M.O.; BITTENCOURT, L.J.

NUNES, M.O.; BITTENCOURT, L.J. En el sendero de lo que transtorna el cuerpo y desordena el comer: los sentidos del descontrol de sí y de las "compulsiones alimentarias". Interface - Comunic., Saude, Educ., v.17, n.44, p.145-57, jan./mar. 2013.

Examinamos el fenómeno de las identidades somáticas comprendidas como nuevas formas de percepción y relaciones socialmente establecidas con el cuerpo, incluso modos alterados de alimentarse, no necesariamente patológicos. Utilizamos una perspectiva teórica fenomenológica e interpretativa centrada en el concepto de corporeidad desarrollado por Thomas Csordas, basado en los conceptos de percepción corporal de Merleau-Ponty y de cuerpo socialmente informado, del concepto de habitus en Bourdieu. Centramos el análisis en narrativas de mujeres que elaboran sus historias de vida a partir de puntos de viraje corporal, que indican dinámicas socioculturales y afectivas corporificadas; significadas a partir de cuestiones étnicas, de clase social y género. Discutimos los paroxismos de la individualización moderna donde, por medio de las compulsiones alimentarias, los cuerpos individuales expresan, significan y revierten los males del grupo.

Palabras clave: Corporeidad. Identidades somáticas. Fenomenología. Relaciones raciales. Compulsion alimentaria. 